\title{
Mathematics and crises
}

\author{
Ole Skovsmose ${ }^{1,2}$
}

Accepted: 2 February 2021 / Published online: 20 February 2021

(C) The Author(s), under exclusive licence to Springer Nature B.V. part of Springer Nature 2021

\begin{abstract}
One can identify at least three different types of relationships between mathematics and crises. First, mathematics can picture a crisis. This is in accordance with the classic interpretation of mathematical modelling, which highlights that a mathematical model provides a representation of a piece of reality, a reality that could be a critical situation such as, for instance, a pandemic. Second, mathematics can constitute a crisis, meaning that mathematics can form an intrinsic part of the very dynamics of a crisis. This phenomenon can be illustrated by the economic crises that spread around the world in 2008. Third, mathematics can format a crisis. This final formulation refers to a situation where a mathematical reading of a crisis brings about ways of acting in the critical situation that might be adequate, but also counterproductive, if not catastrophic. This is illustrated with reference to the potential crises due to climate changes. As a conclusion, the paper addresses the politics of crises, which refers to the power that can be acted out through a crisis discourse in which mathematics may come to play a deplorable role.
\end{abstract}

Keywords Mathematics picturing a crisis $\cdot$ Mathematics constituting a crisis $\cdot$ Mathematics formatting a crisis $\cdot$ Politics of crises

Human influence on nature, the environment, and basic living conditions appears devastating. We will come to face more and more crises going forward. Crises due to drought as well as to floods. Crises due to lack of clean drinking water or other natural resources. Crises due to displacement of people, deportation, immigration. We will see crises due to overpopulation and hunger crises spreading out to more parts of the world. Crises due to increasing inequalities with respect to basic welfare conditions. Crises due to pollution. Crises due to climate change. We will come to witness new patterns of diseases, epidemics, and pandemics which will travel around the planet. Political crises might take new formats, and so might crises caused by violence and war. We are entering a period where crises will

Ole Skovsmose

osk@hum.aau.dk

1 Aalborg University, Aalborg, Denmark

2 Universidade Estadual Paulista (UNESP), Sao Paulo, Brazil 
be more and more frequent, if not a perpetual phenomenon. This is one possible reading of the future. ${ }^{1}$

Instead of crisis, one can also talk about a critical situation. I am not going to present any differentiation between the two notions but use them both as synonyms. ${ }^{2}$ The notion of risk belongs to the same family of notions: a risk can be seen as a potential critical situation.

One can talk about crises in many different ways, such as a personal crisis, a psychological crisis, an identity crisis, and a family crisis, but in this paper, I concentrate on largescale crises by focusing on epidemics as well as financial and environmental crises. Naturally, there are strong connections between large-scale and personal crises. When a country enters a financial crisis, critical situations for families and individuals emerge; some might lose their job, some might need to sell their house, and some might need psychological support. However, the intensive dynamics between macro-crises and microcrises is not the topic of this paper.

I am concentrating here on possible relationships between mathematics and crises. I will refer to three examples, and in this way illustrate the principal point of this paper, namely that one can experience at least three different types of relationships between mathematics and crises. Previously, in Skovsmose (2019), I pointed out that there existed relationships between mathematics and crisis. There I also discussed how such relationships could be approached through critical mathematics education. In the present paper, I concentrate on exploring examples of mathematics-crises relationships.

The first example illustrates that mathematics can picture a crisis. This is in accordance with the classic interpretation of mathematical modelling, which highlights that a mathematical model provides a representation of a piece of reality. This "piece of reality" can be a critical situation, and by investigating its mathematical representation, one might get a better understanding of the crisis itself.

The second example shows that mathematics can constitute a crisis. A mathematical model need not operate as detached from a crisis but can become an intrinsic part of the crisis. Mathematics-based algorithms may provide an underlying dynamic which brings about the crisis. In such a case, mathematics is not picturing a crisis; it becomes an essential ingredient in a crisis. The crisis might not exist without mathematics.

The third example illustrates that mathematics can format a crisis. With this formulation, I have in mind a situation where a mathematical reading of a crisis brings about a way of acting in the critical situation. It might turn out that these actions function adequately and that the crisis comes under control. The opposite might also be the case: the reading might be a misreading, and the actions might be counterproductive. In both cases, the mathematics formats both readings and actions, and in the end, it formats the dynamics of the crisis itself.

We have here three analytical types of mathematics-crisis relationships, but in real-life critical situations, the distinction among the three might be blurred. This will become apparent in the following sections when I illustrate the three relationships by examples. I make this

\footnotetext{
${ }^{1}$ Due to the human influence on the atmosphere, we might witness a new geological epoch that needs a name, the anthropocene. One characteristic of this period is that crises become common phenomena. For the formulation of the concept of anthropocene, see Crutzen and Stoermer (2000); for relating the discussion of the anthropocene to mathematics education, see Coles (2016). See also Bostrom and Cirkovic (2008), who present a range of examples of global risks with catastrophic dimensions, and Klein (2014) and Latour (2018), who present broader political discussions of the issue.

${ }^{2}$ In Skovsmose (2019), I point out some semantic connections between the notions of crisis and critique.
} 
distinction principally in order to refine our analytical interpretations of mathematics-crises relationships. ${ }^{3}$

I conclude the paper by addressing the politics of the crisis. To call something a crisis focusses public attention on the phenomenon. However, what are we to call a crisis, and what not? Who decides what to call a crisis? Many assumptions, presumptions, preconceptions, and particular interests become expressed through a crisis discourse. As part of some such discourses, abominable and cynical ideas can become incorporated (and in some cases normalised), and we need to raise the question to what extent mathematics could come to constitute a part of such discourses.

\section{Mathematics as picturing a crisis}

In the Tractatus, Ludwig Wittgenstein (2002) interprets language as picturing reality. Wittgenstein talks about the language, as he has in mind one specific language. He does not think of any plurality of languages, as he later elaborated on in Philosophical Investigations in terms of language games (Wittgenstein, 1997). In the Tractatus, Wittgenstein specifies the role of the language as to provide representations of reality. This is the essence of what has become referred to as Wittgenstein's picture theory of language. The language Wittgenstein has in mind when talking about the language is mathematics.

If the role of language is to provide pictures, and mathematics is the language, then mathematics does the picturing. This is the role of mathematics, according to the Tractatus. This idea was further elaborated by the logical positivism into the claim: mathematics is the language of science. Wittgenstein's picture theory of language characterises a broad set of views about mathematical modelling.

In order to specify a model, according to such a view, one needs to specify the part of reality that becomes modelled, the mathematical concepts that are going to be applied (parameters, functions, equations, etc.), and the way these entities become related to the features of reality. An important question becomes to what extent a mathematical model provides an accurate picture of the selected piece of reality. ${ }^{4}$

Mathematical modelling of epidemics or pandemics is a developed discipline. ${ }^{5}$ An important parameter in such modelling is the number $R$ that refers to the number of infected persons generated by one infected person. As a further simplification, we can assume that this infection will take place within a certain time unit. If $R$ is bigger than 1 , the epidemic will develop and might get out of control. If $t$ refers to the number of time units, then, the number of newly infected people at time $t, N(t)$, will be $N(t)=R^{t}$. The total number of infected people at the time $t, S(t)$, will then be:

$$
S(t)=N(0)+N(1)+N(2)+\ldots+N(t)=1+R+R^{2}+\ldots+R^{t}=\left(1+R^{t+1}\right) /(R-1)
$$

\footnotetext{
${ }^{3}$ The discussion also relates to investigations of mathematics in action; see, for instance, Ravn and Skovsmose (2019), and Part 4 "Mathematics and Power" in Skovsmose (2014).

${ }^{4}$ As an illustration, a mathematical model has been described as a triple $(R, M, f)$, consisting of a set of empirical objects, $R$, a set of mathematical entities, $M$, and a function $f: R \rightarrow M$, which relates reality and mathematics; see Niss (1989) and Blum and Niss (1991). Specifications of mathematical models have always been accompanied by clarifications of mathematical modelling processes; see, for instance, Blum et al. (1989).

${ }^{5}$ Capasso (2008) provides a careful presentation of the mathematics of epidemics, showing different mathematical approaches. An extensive presentation is also found in Brauer, Castillo-Chavez, and Feng (2019).
} 
The number $N(t)$ will follow an exponential growth pattern; the growth of the total number of infected people, $S(t)$, will also have an exponential format. However, this is a simplified and abstract situation. As an epidemic takes place within a certain population, there is an upper limit to the number of people that can be infected. The graph of the function $N(t)$ will get a bell shape, while the graph of the function $S(t)$ will take an s-shape, like the format of a logistic growth. All this is a gross simplification but illustrates an important point: one way of trying to deal with an epidemic is to reduce the number $R$. This can be done by establishing social distancing or social isolation.

Such mathematical modelling fits Wittgenstein's picture metaphor. Mathematics might describe, more or less reliably, the dynamics of an epidemic. By doing so, the model is not only describing what is actually the case but also what could become the case. ${ }^{6}$ That the mathematical picturing has no influence on the epidemics is obvious. In this case, the language of mathematics seems detached from what it depicts. ${ }^{7}$

On 16 March 2020, the UK Imperial College COVID-19 Response Team (Imperial College, 2020) published their Report 9: Impact of Non-Pharmaceutical Interventions (NPIs) to Reduce COVID-19 Mortality and Healthcare Demand. When the report was published, the coronavirus crisis was still in its initial phase. In many countries, the number of people catching the virus and the number of deaths did not appear alarming, and the governments in some countries such as the USA and the UK had not been prepared to take any particular measures. Both the British Prime Minister Boris Johnson and the USA President Donald Trump found the discourse of the press to be exaggerated, and some commentators and politicians found it even hysterical. In an interview on 28 February 2020, Boris Johnson indicated that washing hands would be an adequate way of dealing with the coronavirus problem. $^{8}$ Then, emerged the report.

The report delineates the possible dynamics of the coronavirus epidemic. With particular reference to the USA and UK, the report states:

The epidemic is predicted to be broader in the US than in GB and to peak slightly later. This is due to the larger geographic scale of the US, resulting in more distinct localised epidemics across states [ ... ] than seen across GB. The higher peak in mortality in GB is due to the smaller size of the country and its older population compared with the US. In total, in an unmitigated epidemic, we would predict approximately 510,000 deaths in GB and 2.2 million in the US, not accounting for the potential negative effects of health systems being overwhelmed on mortality. (pp. 6-7)

This is shocking reading. These are the scenarios that were to be expected, had no measures been taken, and the epidemic developed according to its own dynamics as pictured by the applied mathematical models.

The report, however, presents different future scenarios depending on what measures are taken. It shows both graphically and numerically the differences between the scenario with no

\footnotetext{
${ }^{6}$ In order to describe a dynamic of an epidemic, system dynamics modelling becomes crucial. See, for instance, Duggan (2016).

${ }^{7}$ This appears commonsense when we think of epidemics in biological terms. Kiss, Miller, and Simon (2017) address the mathematics of epidemics on networks. In this case, the situation is quite different, as we are dealing with a situation where mathematics constitutes the epidemic problem. It is through mathematics as well that one needs to address the problem.

${ }^{8}$ See https://www.bbc.com/news/av/uk-politics-51682581/boris-johnson-advises-people-to-wash-hands-toavoid-coronavirus. Accessed 8 May 2020.
} 
precautions implemented, and scenarios where some measures are applied. The report makes evident what can be expected if one implements case isolation, or household isolation, or closing schools and universities, or if one establishes social distancing of more than $70 \%$ of the population. Even in the case that maximum precautions are applied, the prediction looks gloomy. The report concludes:

[... ] that epidemic suppression is the only viable strategy at the current time. The social and economic effects of the measures which are needed to achieve this policy goal will be profound. Many countries have adopted such measures already, but even those countries at an earlier stage of their epidemic (such as the UK) will need to do so imminently. (p. 16)

Soon after the publication of the report, one can observe changes in the official policy in the USA and the UK. Measures were implemented, and social distancing became official policy.

The change of strategies in the two countries is an example of socio-political impacts of a mathematical picturing of a crisis. Naturally, the mathematical modelling needs not be precise. Any picturing depends on assumptions incorporated in the model. The model provided by the Imperial College COVID-19 Response Team might give a disproportionate picture of what might happen: the consequences could turn out to be less sinister; they could also be worse than predicted. A mathematical model provides an attempt at looking into the future, but it is an unreliable look.

The notion of similarity gap refers to the difference between the mathematical picture of reality and the reality itself. Such a gap might be minimal, but this needs not be the case. The existence of similarity gaps is a direct implication of the fact that mathematical models always include simplifications and stipulations. In the case of a pandemic, the similarity gap refers to the difference between the dynamics described by a model and the actual development of the pandemic. It is one thing, however, to acknowledge the existence of a similarity gap; it is quite another thing to estimate the size of such a gap. In cases in which we are dealing with a picturing of an actual situation, a similarity gap can be estimated directly. A quite different situation occurs when we are dealing with predictions. In this case, the most reliable method for estimating the size of a similarity gap seems, unfortunately, to be to wait and see what comes to pass. Whenever we are addressing epidemics or pandemics through mathematical modelling, we have to acknowledge the possibility of even huge similarity gaps. ${ }^{9}$

\section{Mathematics as constituting a crisis}

When shopping in a supermarket, we push the trolley around and fill it with what we think we need. We get to the cashier and put the items on the belt. The cashier passes the items across a barcode reader, and we can pick them up again and put them in the bag. One takes out the credit card, inserts it in the small machine, presses some digits, then an OK, and one has paid for what one has bought.

This appears to be a trivial process. However, complex processes are running beneath the surface of this simple routine. My credit card is identified; the money I have to pay is subtracted from my bank account linked with the card; and the money enters the account of the supermarket. All the transactions are protected by some security measures. This entire

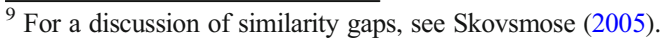


process only operates due to a most complex configuration of mathematical algorithms. The coding and the decoding that are necessary in such transactions are mathematical devices, constructed on top of advanced theoretical insight, for instance, concerning number theory. ${ }^{10}$

In these processes, mathematics forms an integral part. We are not dealing with a mathematical model that just pictures what takes place in the transactions. Mathematics performs the transactions. Mathematics constitutes the processes we are talking about.

Uwe Gellert and Eva Jablonka address two important notions, namely mathematisation and demathematisation. ${ }^{11}$ Their point is that both processes are taking place simultaneously with respect to many daily life practices. Mathematisation can refer to the huge amount of mathematics used in order to complete the economic transactions when paying in a supermarket. Demathematisation refers to the apparent elimination of mathematics from the tangible practice of paying. Previously the cashier had to add up the prices of the items and calculate the correct amount of change. As a control, the buyer could check the calculations. Today, no such explicit mathematics surfaces in the situation. The practice of paying has become demathematised. This demathematisation is made possible precisely due to the mathematisation of the underlying processes.

If we look, not at the supermarket, but at the stock market, we can observe a similar phenomenon. Transactions are again conducted by mathematics-based algorithms. A profound mathematical structuring of the stock market has taken place. There are no real bonds and no real money passed across the tables. Mathematical algorithms drive the processes. Mathematics is not doing any picturing of the stock market transactions but is conducting them. Mathematics constitutes the processes of transaction. One can consider to what extent the whole apparatus of a capitalist economy would function without mathematics constituting a range of its procedures. ${ }^{12}$

When mathematics becomes part of the functioning of economic processes, it also becomes part of the possible dysfunctions of such processes. In the book Weapons of Math Destruction, Cathy O'Neil (2016) discusses the role of mathematics in handling huge data material. The subtitle of her book is How Big Data Increases Inequality and Threatens Democracy. O'Neil was a research mathematician with a promising career in front of her, but she decided to quit her job at the university in order to work at a private hedge fund company. This job included the administration of huge investments, and to do so, mathematical expertise is crucial.

In 2008, after she had worked at the company for about 1 year, the economic crisis hit. This crisis made O’Neil (2016) aware of some important features of mathematical modelling:

That crash made it all too clear that mathematics, once my refuge, was not only deeply entangled in the world's problems but also fuelling many of them. (p. 2)

This is a principal observation: mathematics is not any detached academic discipline; it can be deeply entangled in real-life problems; and it may also be fuelling such problems. By making this observation, O'Neil moves far away from any picture theory of mathematics. A picture

\footnotetext{
${ }^{10}$ See, for instance, Schneier (1996), Skovsmose and Yasukawa (2009), and Stallings (2017).

${ }^{11}$ See Jablonka and Gellert (2007) and Gellert and Jablonka (2009). See also the discussion of mathematical modelling in Jablonka (2010).

${ }^{12}$ In Capitalism and Arithmetic, Swetz (1987) makes a careful study of what can be referred to as the new mathematics of the 15th century. He shows how this mathematics provides means for making accounts and the economic control necessary for coping with the expanding trade of the time.
} 
can be more or less accurate, but it does not become part of what it portrays. However, mathematics may do other things than just picturing. O’Neil continues:

The housing crisis, the collapse of major financial institutions, the rise of unemployment

- all had been aided and abetted by mathematicians wielding magic formulas. (p. 2)

Mathematics has been entangled with housing crises, collapses of financial institutions, and the rise of unemployment. This is a strong claim made with respect to mathematics that often has been considered "innocent and harmless". Such words were used by Godfrey Hardy (1967, p. 141) in A Mathematician's Apology, when he describes the nature of what he thinks of as real mathematics. Contrary to Hardy's position, O’Neil claims that by "wielding magic formulas", mathematics constitutes a range of socio-political and economic crises. ${ }^{13}$ Mathematics not only causes chaos, it also adds to it:

What's more, thanks to the extraordinary powers that I loved so much, math was able to combine with technology to multiply the chaos and misfortune, adding efficiency and scale to the systems that I now recognized as flawed. (p. 2)

How could mathematics come to assume such a role? How could mathematics come to add efficiency and scale to flawed systems? A particular feature of the modern stock market is algorithmic trading. Decisions about buying or selling depend on many factors, which can be systematised and condensed into algorithms, meaning that decisions about selling or buying can be executed automatically. These decisions can concern all the details of the process: the time to complete the business, the price level that is considered acceptable, and the amount of money to be traded. In 2006, a third of all stock market transactions in the European Union and the USA had the form of algorithmic trading. ${ }^{14}$ Algorithmic trading makes it possible for economic transactions to run fast and to be further accelerated. It can accelerate the whole situation out of balance, even causing an economic crash as a consequence.

Naturally, an economic crisis can have different external causes, but as pointed out by O'Neil, we also have to understand its dynamics in terms of the mathematical deep-structuring of economic processes; we have to place a focus on some "magic formulas". The roots of the crisis have to be looked for in dysfunctions in the mathematical machinery that otherwise constitutes the surface of economic normality. With such an interpretation, one can see the economic crisis of 2008 as being constituted by mathematics.

In her book, O'Neil describes other mathematical models brought into operations, not only with respect to economic transactions but applied in all spheres of life, in administration, management, production, surveillance, and military. O'Neil's point is that "many of these models encode human prejudice, misunderstandings, and bias into the software systems that increasingly manage our lives" (p. 3). According to her, such models are causing a range of critical situations for individuals and groups as well as for whole sections in society. Mathematical modelling can be a crisis-generating factor.

\footnotetext{
${ }^{13}$ It might be that O'Neil has something more particular in mind when talking about "magic formulas", thus the Black-Scholes formula plays a crucial role in algorithmic trading; see Chriss (1997) and Harford (2012).

${ }^{14}$ For a detailed presentation of algorithmic trading, see Johnson (2010). See also Miller (2014) for a discussion of mathematics-based risk management.
} 
As an example, one can think of piloting an airplane. ${ }^{15}$ The automatic pilot can take over, but even when the real pilot is in charge, many estimations and manoeuvres are made automatically. The steering by the real pilot is based on a huge number of mathematicsbased automatic processes. The degree of automation gets more and more profound, and any such automatisation is constituted by a configuration of mathematical algorithms. Like any such configuration, unexpected implications might occur. As with financial crashes, so also airplane crashes might have their explanation in some automatised mathematical deepstructuring machinery going awry. ${ }^{16}$

Let me conclude this section by making a general remark about ontology. With respect to mathematics, ontology concerns the questions: What is a mathematical entity? In what sense does mathematics exist? Where is mathematics? A classic answer to such questions was provided by Plato who claimed that mathematical entities, like points, lines, and triangles, have a real existence; however, this existence was not in any physical or empirical world but in the world of ideas. No empirical study of any physical triangle would be able to demonstrate the properties of real triangles. The access to the world of ideas could only be obtained by rationality. Contrary to any Platonic ontology, the discussion in the present section brings me to claim that mathematics constitutes parts of our reality as we experience it in our daily life, buying items at the supermarket being just one example. Furthermore, mathematics not only constitutes features of what we refer to as our regular, routine-like normal life; it also constitutes many crises that we might experience. Mathematics constitutes an integral part of our life-worlds.

\section{Mathematics as formatting a crisis}

Advanced mathematical modelling is used in order to provide weather forecasts. This also applies to long-term forecasting with respect to the future climate of the planet. Such forecasting cannot be rooted in any laboratory experiments. Today the principal way to try to look into the future is to make predictions through enacting some mathematical modelling. This has developed into an advanced discipline, where a range of mathematical topics and techniques are brought together. ${ }^{17}$

According to Dana MacKenzie (2007), a climate model in its simplest form includes four components dealing with the atmosphere, the ocean, the land, and the ice. The atmosphere model tries to grasp the dynamics of the air, and it can be composed of several differential equations. The ocean model tries to comprehend the dynamics of the sea and is also composed of a range of equations. One important feature of water dynamics is the degree of salinity, and this important parameter has to be included in the model. The structure of land is relatively stable, as the positions of continents are not making any rapid movements. There is, however, the amount of ice. The ice model shows obvious changes, which have an impact on, for instance, the dynamics captured by the ocean model. In fact, the models for atmosphere, ocean, land, and ice need to be carefully interrelated in order to establish a reliable climate model.

\footnotetext{
${ }^{15}$ In Skovsmose (2005), I have discussed how mathematics is formatting the airplane companies' approach to the booking of seats.

${ }^{16}$ See Hawkins (2019), who raises the question if the Boeing airplane crashes can be related to the airplane's automation.

${ }^{17}$ See, for instance, Coiffier (2011) and Warner (2011). For any such type of forecasting, system dynamic modelling is crucial; see Duggan (2016) as already referred to.
} 
A climate model includes a multitude of parameters. In no case is it possible to include all possible parameters; a selection is necessary. This selection depends on what one considers important, and on the complexity of the model one is ready to try to build. Any model construction presupposes the making of a number of pragmatic decisions, some of which might be rather arbitrary. The parameters need to be connected by equations, which is also a process that includes decisions. Some connections might represent a profound theoretical insight, while others may have an ad hoc format. In the end, one ends up with a model through which one tries to make predictions with respect to the climate.

Given a set of values of the parameters, the running of the model will give a particular result. It could be with respect to the average temperature at a particular location at a particular time. In order to make a preliminary test of the reliability of the model, one can do some "experimental forecasting": on the basis of information about, say, 2010, one lets the model "predict" the temperature for 2011. This "prediction" gets compared with the already known temperature for 2011. This process continues, and the model is adjusted until we get to the proper forecasting. ${ }^{18}$

When we get to the real forecasting, the climate model gives an indication of what might happen in the future, if no interventions are implemented. However, one can undertake experimentation with the forecasting by changing the value of some parameters and observing the changes in the forecast. Changes of some parameters might bring about a significant change in the output of the model; in such a case, we are dealing with sensitive parameters. By doing systematic experimentation with the model, one can identify a set of sensitive parameters. ${ }^{19}$ This brings about an insight into what possible measures could be taken that could make a difference. Such insight might turn into political recommendations for coping with the climate changes.

This short summary is in accordance with the conception of mathematical modelling as picturing. Nobody would think of climate modelling as doing anything to the climate. But now, look at the following article: "The Mathematical Formatting of Climate Change: Critical Mathematics Education and Post-Normal Science" by Richard Barwell (2013). First the title: Barwell talks about the mathematical formatting of climate changes. But what could he have in mind? In what sense could mathematics format climate changes?

Could it be that descriptive modelling is not just descriptive? Could picturing also be performative? Let us listen to what Barwell (2013) says:

The prediction of likely future course of climate change is based on more advanced mathematics. Developing predictions about future global, regional or local effects of climate change draws on a range of advanced mathematical methods, including mathematical modelling, differential equations, non-linear systems and stochastic processes.

This remark is in accordance with what we already have observed: mathematics constitutes an integral part of any climate model. Mathematics is a necessary tool for making predictions. The whole conception of climate change is bound up on mathematical modelling, as mathematics provides a principal way of trying to look into the climatic future of the planet.

\footnotetext{
${ }^{18}$ This kind of experimental forecasting was an integral part of the construction of the North Sea Model, which was elaborated with the purpose of identifying the best possible fishing policy for the North Sea. For a presentation of the model, see Chapter 18 in Skovsmose (2014).

${ }^{19}$ For a discussion of sensitive parameters in a mathematical model, see Chapter 18 in Skovsmose (2014).
} 
Furthermore, Barwell observes that any mathematics-based identification of climate change reflects not only some possible physical phenomena but also the very nature of the mathematics being used. He highlights that mathematics provides a particular reading of climate change, making space for a selective set of possible actions. In Barwell's (2013) formulation:

Mathematics also formats how we interact with the climate. Through the mathematised, model-based perspective prevalent in climate research, the climate is constructed in particular ways as, for example, measurable, predictable, technical and controllable by humans, rather like the temperature in a high-tech sensor controlled greenhouse. (p. 2)

This is the crucial point: mathematics formats how we interact with the climate. A mathematical model does not only describe a situation or provide a prediction, it forms our perception of the situation and therefore the way we tend to act in the situation. Mathematics formats actions and strategies with respect to climate change. As indicated by Barwell, they could repeat the assumption that we are looking at complications that can be regulated through technical interventions. As a consequence, the climate change becomes constructed as a manageable issue. However, we can never expect mathematics to provide any neutral reading of a critical situation; rather, it associates with some specific perspectives that may serve certain political, economic, or industrial interests. In this sense, one can talk about mathematics as formatting climate changes.

That a mathematical reading of a critical situation formats how we may act in the situation also applies to a pandemic. The mathematical model presented by the Imperial College COVID-19 Response Team (2020) appears a forthright descriptive model: it provides a picture of the situation and prospects for the future. At the same time, it formats the way we are acting in the situation. The model is not only descriptive; it is also performative. The model forms the way we try to handle the pandemic, and this means that it forms the very dynamics of the crises. In the same way as Barwell talks about the "mathematical formatting of climate change", we could talk about the "mathematical formatting of a pandemic".

With reference to Wittgenstein, we initially considered a mathematical model of an epidemic as a picture of the epidemic. However, now we need to recognise that mathematics rather provides a formatting of the epidemic. This might be a more general observation, applying not only to an epidemic but to any form of critical situation. We might be ready to talk about the mathematical formattings of any kind of critical situations. The picture metaphor refers to a particular analytical type of a mathematics-crisis relationship. However, it might turn out that it is not a type but rather a stereotype.

\section{Politics of crises}

Huge political and economic interests are connected to calling something a crisis while presenting other problems in different terminologies. ${ }^{20}$ Powers are exercised through discourses of crises. A discourse can be biased in favour of the world's richer countries. When they face serious problems, it can be referred to as a crisis, while similar problems for

\footnotetext{
${ }^{20}$ The political use of the notion of "crisis" was addressed several times during the Mathematics Education and Society Conference (MES 9) that took place in Volos in Greece. The title of the proceedings is Mathematics Education and Life at Times of Crisis (Chronaki, 2017). Important inputs to the discussion of crises came from Chassapis (2017), Greer, Gutiérrez, Gutstein, Mukhopadhyay, and Rampal (2017), and Parra et al. (2017).
} 
poorer countries can be referred to in other terms, if not simply considered their normality. Eisensee and Strömberg (2007) point out that for every person killed by a volcano, nearly 40,000 people have to die of hunger to get the same probability of coverage in the US television news. In any critical situation, there will emerge a group of crisis deniers. This is the case with respect to the coronavirus epidemic, but it could be with respect to any critical situation. Hunger crises, haunting poorer parts of the world, are confronted by deniers living in affluent environments.

How to prioritise one's actions when facing one or more crises? This can be a decision revealing a range of economic interests, political priorities, and ideological preconceptions. An indication of what this could mean was experienced with respect to the coronavirus pandemic in $2020 .^{21}$

One line of arguing, which we can refer to as the human-centred argument, maintains a clear priority: one first has to save lives. What might be needed in terms of financial resources for resolving the pandemic has to be spent, not only for ensuring the direct medical care but also for ensuring the livelihood of the very many people in precarious situations. They might have lost their jobs and possibilities for getting any form of income during the period when social distancing is maintained. The first priority is to save lives and then later on the task becomes taking care of the economic crisis that has emerged.

Another line of arguing, which we can refer to as the economy-centred argument, claims that the medical precautions taken need to be measured with respect to their economic costs. This means, for instance, that the time period and the severity of social isolation or distancing need to be evaluated, not only with respect to their efficiency in reducing the pandemic but also with respect to their economic consequences. Reference to economy can always mean different things. In the economy-centred argument, it might not be the workers' and poor people's daily economy that are in question, but the economy of bigger companies and bond owners. For the financial institutions, it is crucial that the society gets back to normal as soon as possible.

The direct consequence of the economy-centred argument would be that some people are sacrificed in order to save the economy. The benefit is the economic gain, while the costs are "some people". Around March and April 2020, when the two lines of argument were in circulation in Brazil, right-wing voices on social media stated explicitly that some increase in deaths might not be considered a problem. It was also mentioned that while previously the young people had offered their lives in war, now the time had come for the elderly people to do so. ${ }^{22}$ One can think of such statements as cynical side remarks, but there are economic interests and political powers behind such cynicism. Following the economic-centred argument, some people become labelled as being disposable. ${ }^{23}$

\footnotetext{
${ }^{21}$ In medicine, one finds different versions of cost-benefit analysis applied. While costs are measured in money, benefits can be measured in extra gained life years. This brings about an intensive use of mathematics in order to estimate the amount of gained life years compared to the money invested. For a presentation of ways of completing economic evaluation of health care programmes, see Drummond, Sculpher, Claxton, Stoddart, and Torrance (2015). McKie, Singer, Kuhse, and Richardson (2016) launch an ethical discussion of such approaches. ${ }^{22} \mathrm{See}$, for instance, https://istoe.com.br/dono-do-madero-diz-que-brasil-nao-pode-parar-por-5-ou-7-mil-mortes/; and https://economia.uol.com.br/noticias/redacao/2020/03/24/empresarios-coronavirus-o-que-dizem-criticas. htm. Accessed 8 May 2020.

${ }^{23}$ See Bales (2012) for a discussion of disposable people and slavery in the modern globalised economy.
} 
During the 2020 pandemic, we have heard the economy-centred argument, and I am afraid that we might come to hear it again and again in the future. If we are entering a period with more and more crises appearing, we can expect deep tensions between saving lives and saving money.

Cost-benefit analysis might multiply, and let me refer to a historical example of how such an analysis can end up. In 1968, the Ford Pinto car model was put in production, but it turned out to have a problematic fuel system. In car accidents, the Ford Pinto model tended to catch fire. The question for Ford became whether the car should be redesigned such that the fuel tank was placed in a safer position, or whether the production should just continue. Ford based their decision on an explicit cost-benefit analysis. If they continued with the Ford Pinto model as it was, accidents would happen, and the consequences were estimated to be:

180 burn deaths, 180 serious burn injuries, 2100 burned vehicles. $^{24}$

These estimations are naturally based on an extensive amount of statistics. The total costs of such consequences could be calculated based on the information: 200,000 US Dollars per death, 67,000 US Dollars per injury, and 700 US Dollars per vehicle. The total cost would be 49,500,000 US Dollars. This amount was compared to the costs of redesigning the Ford Pinto model, which was calculated to be $137,000,000$ US Dollars. The cost-benefit analysis gave a clear answer, and the Ford Pinto's production continued unchanged. ${ }^{25}$

In the calculations, Ford stipulated the value of a human life to be 200,000 US Dollars. Such a stipulation can be based on extensive mathematical calculations. The preoccupation with defining the value of a human life has a long history. What it is all about is formulated sharply by Kathrin Hood (2017) in the following way:

Every day, government analysts make calculations about how much human lives are worth compared to the cost of saving or prolonging them. (p. 442)

Hood adds that experts have spent "over a century trying to develop a scientifically sound way to measure the economic value of human life" (p. 442). One can easily see economic reasons for such efforts. Governments are saving or prolonging lives through the healthcare system. However, this is not only a humanitarian act; it is also a business investment. To what extent it is a good business depends on what is spent compared to the value of the lives saved. So we need to know the value of such savings. Similar cost-benefit analysis can be used by companies, as by Ford, for instance. Whenever a production includes some risks for somebody-workers, neighbourhoods, consumers - cost-benefit analyses can come to guide the company's decision-making.

Previously the approach to identifying the value of a human life was to consider what the person was able to produce during the rest of his or her lifetime. ${ }^{26}$ A different approach emerged, one that considered life a commodity like any other commodities, meaning that the value of a life should be identified with the price one is ready to pay for it. This idea has been elaborated through the conception of the value of a statistical life. ${ }^{27} \mathrm{~A}$ recent conceptual

\footnotetext{
${ }^{24}$ For this and the following number information, see Leggett (1999).

${ }^{25}$ For a discussion of the Ford Pinto case, see Birsch and Fielder (1994).

${ }^{26}$ For an elaboration for a particular human-life value model, see Hofflander (1966). Here one gets an impression of the mathematical complexities such a model might include. Critical discussion of some selected life-value models can be found in Linnerooth (1979).

${ }^{27}$ See Value of Human Life. https://en.wikipedia.org/wiki/Value_of_life. Accessed 8 May 2020.
} 
development is found in paying particular attention to the marginal costs of saving a life, considering as well the marginal gains of saving a life. The key notion is the value of a prevented fatality. ${ }^{28}$ Such a conception resonates with the general principle in economics that the maximum profit has to be identified where the marginal costs equal the marginal gains. Defining the value of a human life is an ongoing effort, being developed with extensive use of mathematics. $^{29}$

New crises will appear, new tensions between saving money and saving lives will appear, and mathematical tools for decision-making will be required. Let me make a small thought experiment, indicating how a mathematical life value model could become formulated:

The guiding principle could be the classic one that the economic value of a person is the value of the production that the person would be able to make for the rest of his or her life. I imagine that the modelling includes careful classifications of people in terms of job, education, gender, age, and whatever else, in order at the end to reach the average figure: the economic value of a human life. However, due to the classifications, the model opens up for much more specific estimations. What is the average value of a certain sub-group of people? People with further education, senior people, people with diabetes, etc. In a critical situation, the model might be applicable for pointing out which groups of people are worth saving, compared to the costs of saving them. Through such a modelling, younger people will become more valuable than elderly people; people with more education will be allocated more value than people with less education; healthy people will get more value than people with serious disabilities; and people from some nationalities will be more valuable than people from other nationalities. The model might provoke labelling some groups of people as being disposable.

Due to the degree of sexism and racism that structures the society in question, the model might also lead to the conclusion that men are more valuable than women and that white people are more valuable than black people. As O’Neil also observed, all kinds of preconceptions might become integrated in such a mathematical model, and consequently, all kinds of outputs can be expected. Still, such a model could become a tool for the government's decision-making in a critical situation.

I am deeply concerned that when more crises roll across the world, arguments and actions might be based in such kind of modelling. ${ }^{30}$ Mathematics might create pseudo-rationalities for addressing the dilemma between saving lives and saving money. Mathematics might help to fabricate cost-benefit analysis in a particularly cynical manner. Mathematics may format the way we are acting in critical situations, also in the most abominable and inhuman way.

Acknowledgements I want to thank Richard Barwell, Arindam Bose, Ana Carolina Faustino, Peter Gates, Brian Greer, David Kollosche, Amanda Queiroz Moura, Miriam Godoy Penteado, and Guilherme Henrique Gomes da Silva for their helpful comments and suggestions.

\footnotetext{
${ }^{28}$ For an introductory presentation of such an approach, see Thomas (2018). For an elaborated exposition rich with mathematical details, see Thomas and Vaughan (2015).

${ }^{29}$ The whole approach of putting value on human lives has also been critically addressed. One such attitude is the "vision zero". See Calibaba (2017) and https://en.wikipedia.org/wiki/Vision_Zero. Accessed 8 May 2020.

${ }^{30}$ See also Skovsmose (2020), where I discuss the banality of mathematical expertise.
} 


\section{References}

Bales, K. (2012). Disposable people: New slavery in the global economy (3rd ed.). University of California Press.

Barwell, R. (2013). The mathematical formatting of climate change: Critical mathematics education and postnormal science. Research in Mathematics Education, 15(1), 1-16. https://doi.org/10.1080/14794802.2012. 756633

Birsch, D., \& Fielder, J. H. (Eds.). (1994). The Ford Pinto case: A study in applied ethics, business, and technology. State University of New York Press.

Blum, W., Berry, J. S., Biehler, R., Huntley, I. D., Kaiser-Messmer, G., \& Profke, L. (Eds.). (1989). Applications and modelling in learning and teaching mathematics. Ellis Horwood.

Blum, W., \& Niss, M. (1991). Applied mathematical problem solving, modelling applications, and link to other subjects: State, trends and issues in mathematics education. Educational Studies in Mathematics, 22(1), 3768. https://doi.org/10.1007/BF00302716

Bostrom, N., \& Cirkovic, M. M. (2008). Global catastrophic risks. Oxford University Press.

Brauer, F., Castillo-Chavez, C., \& Feng, Z. (2019). Mathematical models in epidemiology. Springer.

Calibaba, J. (2017). The road to vision zero: Zero traffic fatalities and serious injuries (2nd ed.). CreateSpace Independent Publishing Platform.

Capasso, V. (2008). Mathematical structures of epidemic systems. Springer.

Chassapis, D. (2017). "Numbers have the power" or the key role of numerical discourse in establishing a regime of truth about crisis in Greece. In A. Chronaki (Ed.), Mathematics education and life at times of crisis: Proceedings of the Ninth International Mathematics Education and Society Conference (pp. 45-55). Greece: Volos.

Chriss, N. A. (1997). Black-Scholes and beyond: Option pricing models. McGraw-Hill.

Chronaki, A. (Ed.). (2017). Mathematics education and life at times of crisis: Proceedings of the Ninth International Mathematics Education and Society Conference. Greece: Volos.

Coiffier, J. (2011). Fundamentals of numerical weather prediction. Cambridge University Press.

Coles, A. (2016). Mathematics education in the anthropocene. https://research-information.bris.ac.uk/ws/ portalfiles/portal/80374664/MECT3_v2_May16_1_.pdf. Accessed 15 Aug 2020.

Crutzen, P. J., \& Stoermer, E. F. (2000). The "anthropocene". Global Change Newsletter, 41(17), 17-18 http:// www.igbp.net/download/18.316f18321323470177580001401/1376383088452/NL41.pdf

Drummond, M. F., Sculpher, M., Claxton, K., Stoddart, G., \& Torrance, G. (2015). Methods for the economic evaluation of health care programmes (4th ed.). Oxford University Press.

Duggan, J. (2016). System dynamic modelling with R. Springer.

Eisensee, T., \& Strömberg, D. (2007). News droughts, news floods, and US disaster relief. The Quarterly Journal of Economics, 122(2), 693-728. https://doi.org/10.1162/qjec.122.2.693

Gellert, U., \& Jablonka, E. (2009). The demathematising effect of technology: Calling for critical competence. In P. Ernest, B. Greer, \& B. Sriraman (Eds.), Critical issues in mathematics education (pp. 19-24). Information Age Publishing.

Greer, B., Gutiérrez, R., Gutstein, E., Mukhopadhyay, S., \& Rampal, A. (2017). Majority counts: What mathematics for life, to deal with crises? In A. Chronaki (Ed.), Mathematics education and life at times of crisis: Proceedings of the Ninth International Mathematics Education and Society Conference (pp. 159163). Greece: Volos.

Hardy, G. H. (1967). A mathematician's apology. With a foreword by C. P. Snow: Cambridge University Press.

Harford, T. (2012). Black-Scholes: The maths formula linked to the financial crash. BBC. https://www.bbc.com/ news/magazine-17866646. Accessed 8 May 2020.

Hawkins, A. J. (2019). Deadly Boeing crashes raise questions about airplane automation. The Verge. https:// www.theverge.com/2019/3/15/18267365/boeing-737-max-8-crash-autopilot-automation. Accessed 8 May 2020.

Hofflander, A. E. (1966). The human life value: A theoretical model. The Journal of Risk and Insurance, 33(4), 529-536. https://doi.org/10.2307/251227

Hood, K. (2017). The science of value: Economic expertise and the valuation of human life in US federal regulatory agencies. Social Studies of Science, 47(4), 441-456. https://doi.org/10.1177/0306312717693465

Imperial College COVID-19 Response Team. (2020). Impact of non-pharmaceutical interventions (NPIs) to reduce COVID-19 mortality and healthcare demand. Imperial College.

Jablonka, E. (2010). Reflections on mathematical modelling. In H. Alrø, O. Ravn, \& P. Valero (Eds.), Critical mathematics education: Past, present and future (pp. 89-100). Sense.

Jablonka, E., \& Gellert, U. (2007). Mathematisation - demathematisation. In U. Gellert \& E. Jablonka (Eds.), Mathematization and de-mathematization: Social, philosophical and educational ramifications (pp. 1-18). Sense. 
Johnson, B. (2010). Algorithmic trading and DMA: An introduction to direct access trading strategies. 4Myeloma Press.

Kiss, I. Z., Miller, J., \& Simon, P. L. (2017). Mathematics of epidemics on networks: From exact to approximate models. Springer. https://doi.org/10.1007/978-3-319-50806-1

Klein, N. (2014). This changes everything: Capitalism vs. the climate. Simon and Schuster. https://doi.org/10. 1080/10402659.2015.1130420

Latour, B. (2018). Down to earth: Politics in the new climate regime. Polity Press.

Leggett, C. (1999). The Ford Pinto case: The valuation of life as it applies to the negligence efficiency argument. https:/users.wfu.edu/palmitar/Law\&Valuation/Papers/1999/Leggett-pinto.html. Accessed 8 May 2020.

Linnerooth, J. (1979). The value of human life: A review of the models. Economic Inquiry, 17, 52-74. https://doi. org/10.1111/j.1465-7295.1979.tb00295.x

MacKenzie, D. (2007). Mathematics of climate change: A new discipline for an uncertain century. Mathematical Sciences Research Institute. http://library.msri.org/msri/MathClimate.pdf.

McKie, J., Singer, P., Kuhse, H., \& Richardson, J. (2016). The allocation for health care resources. Routledge.

Miller, M. B. (2014). Mathematics and statistics for financial risk management (2nd ed.). Wiley.

Niss, M. (1989). Aims and scope of applications and modelling in mathematics curricula. In W. Blum, J. S. Berry, R. Biehler, I. D. Huntley, G. Kaiser-Messmer, \& L. Profke (Eds.), Applications and modelling in learning and teaching mathematics (pp. 22-31). Ellis Horwood.

O'Neil, C. (2016). Weapons of math destruction: How big data increases inequality and threatens democracy. Broadway Books.

Parra, A., Bose, A., Alshwaikh, J., González, M., Marcone, R., \& D’Souza, R. (2017). “Crisis” and the interface with mathematics education research and practice: An everyday issue. In A. Chronaki (Ed.), Mathematics education and life at times of crisis: Proceedings of the Ninth International Mathematics Education and Society Conference (pp. 174-178). Greece: Volos.

Ravn, O., \& Skovsmose, O. (2019). Connecting humans to equations: A reinterpretation of the philosophy of mathematics. Springer. https://doi.org/10.1007/978-3-030-01337-0

Schneier, B. (1996). Applied cryptography. John Wiley and Sons.

Skovsmose, O. (2005). Travelling through education: Uncertainty, mathematics, responsibility. Sense Publishers.

Skovsmose, O. (2014). Critique as uncertainty. Information Age Publishing.

Skovsmose, O. (2019). Crisis, critique and mathematics. Philosophy of Mathematics Education Journal, 35.

Skovsmose, O. (2020). Banality of mathematical expertise. ZDM Mathematics Education, 52(6), 1187-1197. https://doi.org/10.1007/s11858-020-01168-4

Skovsmose, O., \& Yasukawa, K. (2009). Formatting power of "mathematics in a package": A challenge for social theorising? In P. Ernest, B. Greer, \& B. Sriraman (Eds.), Critical issues in mathematics education (pp. 255-281). Information Age Publishing.

Stallings, W. (2017). Cryptography and network security: Principle and practice (7th ed.). Pearson.

Swetz, F. J. (1987). Capitalism and arithmetic: The new math of the 15th century. Open Court Publishing Company.

Thomas, J. P., \& Vaughan, G. J. (2015). Testing the validity of the "value of a prevented fatality" (VPF) used to assess UK safety measures. Process Safety and Environmental Protection, 93, 293-298 https://www. sciencedirect.com/science/article/pii/S0957582014000962?via\%3Dihub. Accessed 8 May 2020

Thomas, P. (2018). Calculating the value of human life: Safety decisions that can be trusted. Policy Report 25. University of Bristol. https:/www.bristol.ac.uk/media-library/sites/policybristol/PolicyBristol-Report-April2018-value-human-life.pdf. Accessed 8 May 2020.

Warner, T. T. (2011). Numerical weather and climate prediction. Cambridge University Press.

Wittgenstein, L. (1997). Philosophical investigations. Blackwell Publishers.

Wittgenstein, L. (2002). Tractatus logico-philosophicus. Routledge and Kegan Paul.

Publisher's note Springer Nature remains neutral with regard to jurisdictional claims in published maps and institutional affiliations. 